\title{
1 Analysis of effective environmental flow release strategies for Lake Urmia restoration
}

2

3 Ali Torabi Haghighi ${ }^{*}$, Nasim Fazel ${ }^{1}$, Ali Akbar Hekmatzadeh ${ }^{2}$ and Björn Klöve ${ }^{1}$

$4{ }^{1}$ Water Resources and Environmental Engineering Research Unit, University of Oulu,

5 Finland.

$6{ }^{2}$ Department of Civil and Environmental Engineering, Shiraz University of Technology,

7 Shiraz, Iran.

8

$9 \quad *$ Correspondence to: Ali Torabi Haghighi, Water Resources and Environmental Engineering

Research Group, Faculty of Technology, 90014 University of Oulu, Finland; email: ali.torabihaghighi@oulu.fi

\section{Abstract}

Saline lakes have diminished considerably due to large-scale irrigation projects throughout the world. Environmental flow (EF) release from upstream reservoirs could help conserve and restore these lakes. However, experiences from regions lacking environmental legislation or with insufficient water resources management show that, despite EF allocation, farmers tend to use all available water for agriculture. In this study, we employed a new method for designing environmental flow release strategies to restore desiccated terminal lakes in arid and semi-arid regions with intensive cultivation within the catchment. As a novelty, the method takes into account farmers' water use behavior, return flow from irrigation, interaction with groundwater, evaporation together without considering any detail of each and natural flow regime in upstream systems to design an optimum monthly EF release strategy for reservoirs. We applied the method to the water resource system of Lake Urmia, once the largest saline 
lake in the Middle East and now one of the most endangered saline lakes in the world. The analysis showed that the EF released is exploited by lowland farmers before reaching Lake Urmia and that inflow to the lake from some rivers has decreased by up to $80 \%$. We propose a new EF release strategy that requires a considerable change in practice whereby water is released in the shortest possible time (according to reservoir outlet capacity) during the period of lowest irrigation demand in winter. Restoring the lake to minimum ecological level would require 2.4-3.4 $\mathrm{km}^{3} \mathrm{EF}$ allocation by different methods of release based on the recent condition (2002-2011) of the lake.

Key words: Lakes, water scarcity, agriculture, irrigation, compliance.

\section{Introduction}

Due to increased irrigation in arid and semi-arid regions, most closed lakes with intensive agriculture in their catchment are decreasing in size. The Aral Sea in central Asia and Lake Chad in Africa are two well-known examples of such lakes with severe water level decline (Torabi Haghighi and Kløve, 2017). In Iran, the lakes and wetlands drying out include e.g., Lake Urmia, Lake Hamoun, Gavkhuni marsh , and Hoor-Al-Azim wetland (Madani., 2014). Lake desiccation is typically accompanied by other environmental problems such as groundwater decline, river flow reduction, reduced water quality, habitat loss, land subsidence, and dust and sand storms.

Lake Urmia has received most research attention, as it is the largest hypersaline lake in the Middle East and has been shrinking dramatically since 1995, with this desiccation mainly being attributed to anthropogenic causes (Abbaspour et al., 2012; Hassanzadeh et al., 2012; UNEP \& 
51 GEAS, 2012; Fathian et al., 2014; Madani, 2014; Tourian et al., 2015; Fazel et al., 2017a;).

52 The total cultivated area in the lake catchment has increased from $150 \mathrm{~km}^{2}$ in 1980 to $400 \mathrm{~km}^{2}$ in 2007 and is considered the main reason for lake drying (Nouri et al., 2017). The water level

54 decline and the related environmental crisis have been widely reported (Abbaspour \& 55 Nazaridoust, 2007; Karbassi et al., 2010; Zarghami, 2011; Hassanzadeh et al., 2012; UNEP \& 56 GEAS, 2012; Kakahaji et al., 2013; Fathian et al., 2014; Tourian et al., 2015). Thus, lake restoration is now a major task for governmental and non-government organizations, in Iran and elsewhere (Hassanzadeh et al., 2012; Fathian et al., 2014).

59

Environmental flow (EF) is a tool for assigning water release from dams to restore lake inflows, in order to increase lake levels. EF regimes can be designed to mimic natural flow regimes (Poff et al., 1997; Lytle and Poff, 2004; Torabi Haghighi and Kløve 2015) or to meet specific flow targets (Poff et al., 1997; Lytle and Poff, 2004). In arid regions, EF allocation must also consider water consumption patterns in order to be successful, as shown by Torabi Haghighi and Kløve (2017). The main objective of the present work was to design an EF release scheme for Lake Urmia that can achieve the minimum ecologically acceptable water level of about 1274.1 masl (meter above sea level), as proposed by Abbaspour and Nazaridoust (2007). The methodology presented builds on recent work on EF regimes (Torabi Haghighi \& Kløve, 2017), on the sensitivity of lakes to flow regime change (Torabi Haghighi \& Kløve 2015) and lake hydrogeography (Torabi Haghighi et al., 2016).

\section{Material and method}

\subsection{Study area}


Lake Urmia is a large (maximum $6000 \mathrm{~km}^{2}$ area) hypersaline lake in north-west Iran, extending from $37^{\circ} 06^{\prime} 15^{\prime \prime}$ to $38^{\circ} 15^{\prime} 15^{\prime \prime} \mathrm{N}$ and from $45^{\circ} 00^{\prime} 13^{\prime \prime}$ to $45^{\circ} 55^{\prime} 20^{\prime \prime} \mathrm{E}$. The lake is a Natural Park and UNESCO biosphere reserve (since 1976), and was listed as a Ramsar site in 1971 (Nouri et al., 2017). The lake and its $51,876 \mathrm{~km}^{2}$ catchment (Fig. 1) are important for 6.5 million people whose main sources of income are agriculture and industry. Cropland and orchards comprise about $10 \%$ of the catchment area, but consume more than $90 \%$ of all renewable water resources in the Lake Urmia basin (Fazel et al., 2017b). Surface water provides about $60 \%$ of agricultural water demand (OWWMP, 2011a), via reservoirs, diversion dams, canals, and pumps from rivers and streams. The construction of large dams along the main stream and major tributaries has significantly changed the natural flow regime of the basin's rivers. Mean annual precipitation in the basin is about $357 \mathrm{~mm}$, mainly falling in winter and spring (Fazel et al., 2017a). Annual potential evaporation in the area varies from $1050 \mathrm{~mm}$ in the north-east to $1550 \mathrm{~mm}$ in the south-west (OWWMP, 2011b). General overview of irrigation, allocation mechanisms and responsible institutions in Urmia lake has been presented in Annex 1.

The main rivers in Lake Urmia basin are the Zarinehroud, Siminehroud, Mahabadchay, Gadarchay, Ajichay, Zulachay, Brandooz, Qalechay, Laylan, Nazluchay, and Rovzehchay. More than $75 \%$ of lake inflow is supplied by six rivers (Fig. 1). In this study, we used data from for each sub-basin of the major rivers (the closest gauge to Lake Urmia and one gauge from the upstream, Fig. 1a). Based on the recorded flow at the last station on each river flowing into the lake, mean annual available flow in the Lake Urmia basin for the four decades since 1971 has been 4.4, 5.0, 3.4 and $2.3 \mathrm{~km}^{3}$ (Fig. 1b-e). During this time, the total cultivated area has expanded significantly (approximately tripling in less than three decades), resulting in irrigation water consumption increasing annually from 1.8 to $5.5 \mathrm{~km}^{3}$ (Nouri et al., 2017). 


\subsubsection{Environmental flow scenarios}

The approach developed here to assess EF builds on a few hydrological statements and facts.

We assumed that lake inflow is the response of its upstream basins to rainfall. Moreover, in pristine basins, the flow rate typically increases along major rivers due to increasing contributing area (Eq. 1) and the flowrate at headwater (upstream) gauges is a fraction of that at downstream gauges. Thus the flow rate at downstream gauges is a function of that at upstream gauges (where the downstream gauge is the last gauging point on the river before discharging into the lake). This (for month i) can be expressed as:

$Q i_{\text {downstream }}=f\left(Q i_{\text {upstream }}\right)$

Over time, due to increasing water consumption by the agricultural sector, the flow regime changes, since, farmers use as much water as possible during the irrigation season to expand their business and upgrading the facilities for irrigation. Thus, the water consumption in the lower part of basin is then a function of available water in the river (Eq. 2). Consequently, the flow rate at downstream gauges (here inflow to Lake Urmia) is the difference between upstream gauge and water consumption amounts (Eq. 3), which can be expressed by the functions (for month i):

122 In seasonally irrigated regions, the monthly relationship between upstream and downstream flow can be divided into two seasons: natural season, where the upstream and downstream monthly discharge has better fits the relationship in Eq. 1, and modified season, where the 
upstream and downstream monthly discharge better fits the relationship in Eq. 2. Thus, the monthly contribution (percentage) of upstream flow to downstream flow (here called $\mathrm{P}_{1}-\mathrm{P}_{12}$ ) can be calculated by using one of Eq. 1 or 2 (which has higher monthly regression coefficient), depending on the status of the water system (pristine or extensively irrigated). The main advantage of these functions (Eqs. 1-3) is that, the approach consider the system as a black box. The water release (EF) to the lake can be affected by several factors such as return flow from irrigation, interaction with groundwater, evaporation and so on. Our functions (Eqs. 1-3) and our approch, however, present all potential flows and process without the need on detail information of individual flow processes and parameters.

For lake restoration (the target for allocating EF in Lake Urmia basin), the optimum condition for EF release is to maximize the amount of flow at downstream gauges, i.e., inflow to the lake. Assuming a monthly EF release (Eq. 4) for different periods (1-12 months), each month will have a release coefficient $\left(\mathrm{C}_{\mathrm{i}}\right)$ that defines the monthly contribution to annual release (Eq. 4). We considered the annual $\mathrm{EF}\left(\mathrm{EF}_{\mathrm{An}}\right)$ to be released based on two monthly distribution approaches: I) uniform release and II) weighted release. In method I, we considered uniform monthly release, whereby $\mathrm{EF}_{\mathrm{An}}$. is divided by number of months and an equal magnitude of $\mathrm{EF}$ is released during each month of the release period (Eqs. 4 and 5). In method II, we considered weighted monthly release, where the monthly release coefficient $\left(\mathrm{C}_{\mathrm{i}}\right)$ is based on the contribution of upstream gauges to downstream gauges $\left(\mathrm{P}_{1}-\mathrm{P}_{12}\right)$ for each month (Eqs. 4 and 5). In this method, the months in which upstream flow make a greater contribution to downstream flow (larger $\mathrm{P}_{\mathrm{x}}$ or lower irrigation effect in this case) are a higher priority for release (coefficient $\mathrm{C}_{\mathrm{i}}$ is greater):

$$
E F_{M R_{i}}=C_{i} \times E F_{A n} .
$$

$148 \quad C_{i}=\left\{\begin{array}{c}\text { Method I: } \frac{1}{n} \\ \text { Method II: } \frac{P_{i}}{\sum_{j=1}^{n} P_{j}}\end{array}\right.$ 
where $\mathrm{EF}_{\mathrm{MRi}}$ is monthly environmental flow release at the upstream point (in $i^{\text {th }}$ month), $\mathrm{C}_{\mathrm{i}}$ is monthly release coefficient for month $i, \mathrm{EF}_{\mathrm{An}}$. is the annual $\mathrm{EF}$ allocated, $\mathrm{n}$ is the number of months during the release period (can vary between 1-12 months), and $\mathrm{P}_{\mathrm{i}}$ is the contribution of upstream flow to downstream flow.

The target for EF release is to increase water levels and restore the lake and the main goal of the EF regime is maximizing inflow to the lake. By considering this fact and based on Eqs. 4 and 5, different options for monthly EF release were generated. Each release period included the months with the greatest contribution to lake inflow. For example, if the ranking of monthly contribution in descending order were May, April, March, February, January, December, June, November, October, July, August and September, the four-month release period would be February-May (i.e., May, April, March, and February).

Using the two methods (I, II) developed for water release and considering the period for release, we developed two groups of monthly EF release: short-period release and annual release. In short-period release, we assumed $\mathrm{EF}_{\mathrm{An}}$. release in a period of 1-6 months and with nine different options for this monthly release: (monthly release (same for both methods), and four uniform (Method I) and four weighted (Method II) release options for 3-, 4-, and 5-month release). For annual release, in addition to one uniform and one weighted release, we developed another annual release scenario based on the Tennant method (Tennant 1976), which is the recommended method in Iran (Tharme, 2003). Based on the Tennant method, EF in the Lake Urmia basin must be released during two periods (April-September (60\%) and October-March (40\%)). Thus in total, we had 12 different release options (nine short-period and three annual releases). For each option, we had a monthly distribution of release as: 
where MEFU is the distribution of of monthly release of EF at the upstream and $\mathrm{c}_{\mathrm{i}}$ is the percentage of monthly release upstream for month $i$.

Net monthly EF release is dependent on the amount of annual EF $\left(E F_{A n .}\right)$ allocated by the decision maker:

$\mathrm{NMEFU}=\left\{\mathrm{NMEFU}_{1}, \mathrm{NMEFU}_{2} \ldots \mathrm{NMEFU}_{\mathrm{i}} \ldots \mathrm{NMEFU}_{11}\right.$ and $\left.\mathrm{NMEFU}_{12}\right\}$

NMEFU $_{i}=c_{i} \times E F_{A n}$

$\sum_{i=1}^{i=12} \mathrm{NMEFU} \mathrm{i}=E F_{A n}$

where $\mathrm{NMEFU}_{\mathrm{i}}$ is net available EF upstream in month $i$.

Due to hydrological responses and also water consumption of sub-basins between upstream gauge and downstream gauge (closest gauge to the lake), part of this NMEFU will be lost depending on the month. By considering the number of months, the inflow to the lake is a portion of NMEFU:

$\mathrm{NMEFL}=\left\{\mathrm{NMEFL}_{1}, \mathrm{NMEFL}_{2}, \ldots, \mathrm{NMEFL}_{\mathrm{i} .}, \ldots . ., \mathrm{NMEFL}_{11}\right.$ and $\left.\mathrm{NMEFL}_{12}\right\}$

$\mathrm{NMEFL}_{\mathrm{i}}=\mathrm{P}_{\mathrm{i}} \times \mathrm{NMEFU}_{\mathrm{i}}$

where $\mathrm{P}_{\mathrm{i}}$ is the contribution of upstream flow to downstream flow (obtained from either Eq. 1 or Eq. 2) and NMEFL is the net monthly EF successfully discharged into the lake during month $i$.

Total inflow to the lake $\left(\mathrm{I}_{\mathrm{i}}\right)$ is then the sum of current monthly inflow to the lake and net monthly EF:

$\mathrm{I}_{\mathrm{i}}=\mathrm{MI}_{\mathrm{i}}+\mathrm{NMEFL}_{\mathrm{i}}$

where $\mathrm{MI}_{\mathrm{i}}$ is monthly flow to the lake (here the monthly time series of lake inflow during 20012010 was considered, because it represents a period of major modification in the river basin following dam construction; see Fig. 1f)) and NMEFL is the net monthly EF successfully discharged to the lake during month $i$, which is dependent on annual $\mathrm{EF}$ ( $\mathrm{EF}_{\mathrm{An} .}$ in $\mathrm{Eq} .9$ ), the 
EF release strategy upstream (Eq. 6), and the contribution of upstream flow to downstream

198

199

200

201

202

203

204

205

206

207

208

209

210

211

212

213

214

215

216

217

218

219

220

221 flow.

To find the best monthly EF release strategy, we calculated the equilibrium water level (EWL) for different values of $\mathrm{EF}_{\mathrm{An}}$. from 0.2 to $3.4 \mathrm{~km}^{3}$ at $0.1 \mathrm{~km}^{3}$ volume intervals (31 different annual EF magnitudes), through water balance simulation (in total $372(31 \times 12)$ scenarios). EWL was taken as mean water level of the lake in each scenario when the lake reached equilibrium conditions (Torabi Haghighi and Kløve, 2015). To find EWL, the water balance simulation run was repeated (with same time series of rainfall, evaporation, and inflow for 2001-2010, plus relevant monthly EF) until the difference between mean water level of the lake during two continuous runs was less than $0.05 \%$. The mean water level for the last run was taken as EWL. Finally, we estimated the amount of water required to reach the minimum ecological level of Lake Urmia (1274.1 masl; Abbaspour and Nazaridoust, 2007) for different EF release scenarios.

\subsubsection{Water balance simulation of the lake}

To evaluate the performance of EF release scenarios, we used a monthly time step water balance simulation (Torabi Haghighi and Kløve 2015):

$\mathrm{V}_{\mathrm{i}+1}=\mathrm{V}_{\mathrm{i}}+\left(\Sigma \mathrm{Q}_{\mathrm{I}}-\Sigma \mathrm{Q}_{\mathrm{O}}\right)_{\mathrm{i}}$

$\Sigma \mathrm{Q}_{\mathrm{I}}=\mathrm{R}_{\mathrm{I}}+\mathrm{P}_{\mathrm{I}}+\mathrm{G}_{\mathrm{I}}$

$\Sigma \mathrm{Q}_{\mathrm{O}}=\mathrm{R}_{\mathrm{O}}+\mathrm{E}_{\mathrm{O}}+\mathrm{G}_{\mathrm{O}}$

where $R_{I}$ is lake inflow, $P_{I}$ is precipitation on the lake, $G_{I}$ is lake groundwater inflow, $R_{O}$ is surface water lake outflow, Eo is lake evaporation, $G_{0}$ is groundwater outflow, and $V_{i}$ and $V_{i+1}$ are lake volume on the first day of the current and next month.

In Lake Urmia groundwater exchange is very low, due to a dense sediment with low permeability deposited on the bed of the lake (OWWMP, 2011), so we set Go and GI equal to 
zero. As Lake Urmia is a closed system, the outflow of the system is only evaporation $\left(\mathrm{E}_{\mathrm{O}}\right)$ and

Ro was thus also set at zero. This reduced the monthly balance equation to:

$\mathrm{V}_{\mathrm{i}+1}=\mathrm{V}_{\mathrm{i}}+\left(\mathrm{I}+10^{-6} \times(\mathrm{P}-\mathrm{c} \times \mathrm{E}) \times \mathrm{A}\right) \mathbf{i}$

225

226

227

228

229

230

231

232

233

234

235

236

237

238

239

240

241

242

243

244

245

246

where $V_{i}$ and $V_{i+1}\left(\mathrm{~km}^{3}\right)$ is lake volume on the first day of the current and next month, $V_{i}\left(\mathrm{~km}^{3}\right)$ ( $\mathrm{i}^{\text {th }}$ month of simulation), $\mathrm{P}$ and $\mathrm{E}$ ( $\left.\mathrm{mm} / \mathrm{month}\right)$ are rainfall and evaporation in the current month, $\mathrm{A}\left(\mathrm{km}^{2}\right)$ is lake area in the current month, $\mathrm{I}\left(\mathrm{km}^{3}\right)$ is lake inflow, and $\mathrm{c}$ is a pan coefficient to convert from pan evaporation to evaporation from a free water body surface. The recommended coefficient for a class A land evaporation pan is 0.7 (Kohler et al., 1955,Webb, 1966). The water balance simulation was performed based on the lake hypsometric curve developed by Sima and Tajrishi (2013) (see Fig. 2d) and flow and climate data for the last decade (2001-2010) that stabilized Lake Urmia in its current situation (Fig. 2), because in that period inflow to the lake was lowest (Fig. 1e). We knew that the flow change during this period resulted from river modification by dams and water development, as most dams were constructed before this period (Fig. 1f). Rainfall and evaporation from the lake area (Fig. 2a and b) and monthly inflow to the lake (sum of all available flow data for the closest gauges on each river flowing to the lake; Fig. 2c) for this period were used to simulate the lake water balance.

Using the Nash-Sutcliffe model efficiency coefficient (Eq. 17), efficiency of simulation model was evaluated (Menberu et al. 2014).

$$
E=1-\frac{\sum_{1}^{n}\left(W L_{o b s}-W L_{s i m}\right)^{2}}{\sum_{1}^{n}\left(W L_{o b s}-W L_{\text {ave }}\right)^{2}}
$$

where $\mathrm{WL}_{\mathrm{obs}}$ is observed water level in the lake, $\mathrm{WL}_{\text {sim }}$ is simulated water level in the lake, $\mathrm{WL}_{\text {ave }}$ is mean observed water level in the lake, and $\mathrm{n}$ is number of months in the simulation. The simulation code was validated using observed water level data for the period 2001-2009. To validate the simulation, the observed lake water level on September 22, 2000 was defined 
as lake initial condition for simulation. Then by using time series of rainfall, inflow, and evaporation (Fig. 2 a-c), the monthly lake water levels for the period 2000-2009 were simulated (Fig. 2e). The modeled water levels showed a good fit with the observed data as the Nash-

\section{Results and discussion}

\subsection{Changes in hydrological responses in sub-basins after dam construction}

For all major rivers in Lake Urmia basin, over time the relationships of flow rate at upstream and downstream gauge were changed. Over time, the number of months with a natural response (stronger relationship in Eq. 1) decreased and the number with a modified response increased (stronger relationship in Eq. 2). This is well demonstrated by the largest river, Zarinehroud

(Fig. 3). It is clear from the diagram that, before 1981, in all 12 months the contribution to lake inflow was a function of upstream flow at the Sariqamish gauge. Thus the blue lines, which represent the results of regression for Eq. 1, had a stronger regression coefficient than the red lines (part I in Fig. 3a-1). During the second, third and fourth periods, the number of months with a stronger regression in Eq. 1 (blue lines) decreased to 10, 8, and 6, respectively (parts II, III, and IV in Fig. 3).

In the Zarinehroud river basin (During recent period (2002-2011)), where there is large-scale irrigation in July-December, the flow reduction between upstream and lake inflow (which represents water consumption) was a function of the upstream gauge flow (part IV, Fig. 3j, k, 1, a, b and c; red lines show higher correlation coefficient $\left(\mathrm{R}^{2}\right)$ ). This clearly confirms that water consumption is currently a function of available water in the river and that most available water 
in the river during these months (those with red lines in Fig. 3) will be used for irrigation even

272

273

274

275

276

277

278

279

280

281

282

283

284

285

286

287

288

289

290

291

292

293

294

295

if the water is released as EF.

Based on similar evaluation of relationship between flow at upstream and downstream gauges (Eqs. 1 and 2), we found that, over time, the hydrological response during the irrigation season changed considerably from the natural response to a new pattern of flow for all major rivers in the Lake Urmia basin (Fig. 4). The greatest river regime alteration was observed in the river Ajichay, for the period 1984-1992, in 11 months of the year Eq. 1 showed a better regression (blue circles in Fig. 4b1), while during 2002-2010, after significant river modification, there were pristine flow conditions in only four months (blue circle in Fig. 4b2).

\subsection{Possible scenarios for releasing EF}

Based on the overall results of monthly regression (Eqs. 1 and 2) in the Lake Urmia basin, the monthly contribution of upstream gauges to lake inflow was estimated for 10 major rivers (Zarinehroud, Siminehroud, Mahabadchay, Gadarchay, Ajichay, Zulachay, Barandooz, Qalechay, Nazluchay and Rovzehchay) for the current situation in Urmia basin (2001-2010). The monthly ranking (descending order) in terms of contribution of upstream gauges discharge to lake inflow was May, April, March, February, January, December, November, June, October, July, August and September, for which discharge was 94.5\%, 87.5\%, 83.8, 69.6\%, $58.8 \%, 53.9 \%, 34.1 \%, 34.0 \%, 14.1,11.2 \%, 9.0 \%$, and $8.2 \%$, respectively. Thus, the contribution of headwaters to lake inflow is lowest during the irrigation season (June-October), while the majority of the upstream flow (54-95\%) is discharged to Lake Urmia during winter and spring, due to high soil moisture, high rainfall, low temperatures, and farmers not using river flow for irrigation. These results indicate that if the annual allocated $\mathrm{EF}_{\mathrm{An}}$ release occurred during May, more than $94 \%$ of flow would be discharged to the lake, while water release in 
September would result in less than $9 \%$ of flow reaching the lake. By considering descending

297

298

299

300

301

302

303

304

305

306

307

308

309

310

311

312

313

314

315

316

317

318

319

320

order of percentage monthly contribution (and considering Eqs. 4 and 5), 12 different options

(A-L) for monthly EF release were generated (Fig. 5). Each release period included the months with the greatest contribution to lake inflow. The EF release options A-L were calculated as monthly percentage, considering different magnitudes of $\mathrm{EF}_{\mathrm{An}}$ (31 different magnitudes from 0.20 to $3.2 \mathrm{~km}^{3}$ at $0.1 \mathrm{~km}^{3}$ intervals), which resulted in 372 different scenarios (using Eqs. 7 and 8) for EF release.

\subsection{Lake water level simulation and performance of EF scenarios}

In total, 372 scenarios for water balance simulation for Lake Urmia were developed by using all 372 EF release scenarios, which were added to lake inflow during 2000-2010 (see Fig. 2c) and combined with other components of water balance: rainfall (see Fig. 2a) and evaporation (see Fig. 2b). Equilibrium water level (1269.6 masl) for the period 2001-2010 was considered as the initial condition for simulation of EF scenarios (Fig. 6a).

The EWL was dependent on the magnitude of $\mathrm{EF}_{\mathrm{An}}$ and $\mathrm{EF}$ release (Figs. 7). For instance, for $3.0 \mathrm{~km}^{3}$ of EF, EWL was 1272.51, 1274.23, 1275.22 and 1277.22 masl for EF release options A, C, G, and L, respectively (Fig. 6d). For $2.0 \mathrm{~km}^{3}$ of EF, the corresponding EWL values were $1271.58,1272.47,1272.94$ and 1273.78 masl, respectively, and for $1.0 \mathrm{~km}^{3}$ of EF they were 1270.58, 1271.05, 1271.27 and 1271.58 masl, respectively (Fig. 6a).

Overall, the results showed that EF releases based on the Tennant method (release option A in Fig. 5) and uniform annual release (EF release option B) are the most inefficient methods. Decreasing the period of EF release led to increasing inflow to the lake and higher EWL (Fig. 7). Releasing the whole EF during May (release option L) was most effective for lake level restoration. The possibility of achieving this form of EF release will depend on dam and 
reservoir outlet capacity. Overall, according to our results, the best time for EF release is during winter and spring (November-May). The reason is that, during this period, soil moisture content is high (rainfall season) and temperature and evapotranspiration are low (winter), so agricultural water consumption is low and the majority of the EF released will reach the lake. Among the annual release options (A, B and C in Fig. 5a), the EF release based on the weighted scheme (option C) showed a considerable increase in lake water level compared with options A and B (compare lines B and C in Fig. 7). As can be seen, the most increase in water level occur after switching the EF release options from B to $\mathrm{C}$. The advantage of the designed EF release is clearly shown by the increase in lake water level (e.g., $1.6 \mathrm{~m}$ increase in water level for $3.4 \mathrm{~km}^{3}$ as annual EF; see Fig. 7). The designed EF release showed better efficiency when the magnitude of annual EF increased (see the length of parallel lines in Fig. 7, each representing one magnitude of annual EF). By decreasing the release period, the difference between EWL in method I (uniform release) and II (weighted release) was decreased, as can be seen by comparing the difference between options B and C (twelve-month release) and options D and E (six-month release) or options J and K (three-month release) (Fig. 7).

The choice of EF regime scenario had a considerable effect on lake level. The same target point (lake re-creation by reaching a certain water level) could be obtained with different EF releases and magnitudes (Fig. 7). The common part of the vertical parallel line in Fig. 7 reveals how the magnitude of EF can be minimized for a certain target point (lake re-creation). For instance, reaching a level of 1272.8 masl (as EWL) can be achieved by releasing $1.6 \mathrm{~km}^{3}$ (using EF release option L) or $3.2 \mathrm{~km}^{3}$ (using release option A) (following the red line in Fig. 7). Saving $1.8 \mathrm{~km}^{3}$ water through a careful EF release policy would be equal to irrigation for 150000 ha agriculture land and jobs for about 10000 people in Lake Urmia basin. The design of EF regimes is a fundamental issue for lake rehabilitation, by optimizing available water resources. 
Nazaridoust. 2007). To reach to this target water level (from the recent state of the lake during 2001-2010 (EWL=1269.6 masl)), reservoirs need to release at least $2.4 \mathrm{~km}^{3}$ in the best release policy for EF (release option L, see black dashed line in Fig. 7). Any change in EF release (e.g., from option L to option A) would need more water to stabilize the lake at the minimum ecological level. For example, the magnitude of annual allocated EF to stabilize the lake at 1274.1, are 2.7 and $3.0 \mathrm{~km}^{3}$ water for release options E and C, respectively (Fig. 7).

\subsection{Environmental flow release for lake restoration or river ecosystems?}

According to past studies, the main concern in Iran is Lake Urmia restoration, without much focus on river ecosystems (Abbaspour \& Nazaridoust, 2007; Karbassi et al., 2010; Zarghami, 2011; Hassanzadeh et al., 2012; Kakahaji et al., 2013; Fathian et al., 2014). Therefore, the present work concentrated on lake recreation by designing a EF release regime based on river modification and changes in hydrological regime of sub-basins. As our results showed, the best EF regime was to release the allocated EF in the greatest possible amount during the shortest possible period, for example May. Undoubtedly, the major criticism of this kind of release would be that it neglects riverine ecosystems. As shown in the past decade, in most of the months water consumption is a function of available water in the river as seen increasing red squares on the right-hand side of Fig. 4 compared with the left for major rivers in Lake Urmia basin. Thus, discharging EF water to the lake during the irrigation season (red-square months in Fig. 4) would not assist in lake restoration. Furthermore, more intensely irrigated areas are located near the lake (Fazel, et al. 2017b), which are mostly irrigating by river flow. Therefore, meeting riverine ecological demands. 


\section{Conclusions}

Restoration of Lake Urmia is an urgent issue. Regulation of rivers (as major water supplier for the lake) have led to increased water consumption and shrinking of the lake. The results show that farmers use as much water as possible during the irrigation season (i.e., the surface water consumption is a function of available water) and often do not comply with regulations. Consequently, the relationship between lake inflow and upstream flow changes over time. Due to the large size of the Urmia basin, a large number of beneficiaries and lack of legislation, the control of water consummation in the basin is difficult or impossible. When allocated EF is released during the irrigation season, it will be used mainly for more irrigation and farming. This tendency is a threat to most closed lake systems that are located downstream of major irrigation areas on fertile plains such as Lake Urmia. Beside the need to implement policies and incentives to reduce the irrigation demand, the optimum monthly EF allocation is important and can lead to a more efficient restoration for the lake. For Urmia lake the best period for EF release is between Nov-May when the crop water demand is low. With the allocated EF, the lake at minimum ecological level can be established at $2.4-3.3 \mathrm{~km}^{3}$. The method shows by using the black box system between upstream and downstream flow regime, we could consider overall change on upstream flow through the passing watershed which is affected by different interaction like account farmers' water use behavior, return flow from irrigation, interaction with groundwater, evaporation together without considering any detail of each .

\section{References}

Abbaspour, M., Javid, A.H., Mirbagheri, S.A., Givi, F.A., Moghimi, P., 2012. Investigation of lake drying attributed to climate change. Int.J.Environ.Sci.Technol. 9, 257-266. 
Abbaspour, M., Nazaridoust, A., 2007. Determination of environmental water requirements of

Fathian, F., Morid, S., Kahya, E., 2014. Identification of trends in hydrological and climatic variables in Urmia Lake basin, Iran. Theoretical and Applied Climatology., 1-22.

Fazel, N., Berndtsson, R., Uvo, C. B., Madani, K., Kløve, B., 2017a. Regionalization of precipitation characteristics in Iran's Lake Urmia basin. Theoretical and Applied Climatology. $1-11$.

401

Fazel, N., Torabi Haghighi, A., Kløve, B., 2017b. Analysis of land use and climate change 402 impacts by comparing river flow records for headwaters and lowland reaches. Global and 403 Planetary Change 158C (2017) pp. 47-56.

Hassanzadeh, E., Zarghami, M., Hassanzadeh, Y., 2012. Determining the Main Factors in 405 Declining the Urmia Lake Level by Using System Dynamics Modeling. Water Resour.Manage. 406 $26,129-145$.

407

Kakahaji, H., Banadaki, H.D., Kakahaji, A., Kakahaji, A., 2013. Prediction of Urmia Lake Water-Level Fluctuations by Using Analytical, Linear Statistic and Intelligent Methods. Water Resour.Manage. 27, 4469-4492.

410 Karbassi, A., Bidhendi, G.N., Pejman, A., Bidhendi, M.E., 2010. Environmental impacts of 411 desalination on the ecology of Lake Urmia. J.Great Lakes Res. 36, 419-424. 
414 Madani, K., 2014. Water management in Iran: what is causing the looming crisis? 415 J.Environ.Stud.Sci. 4, 315-328.

416 Menberu, M.W., Torabi Haghighi, A., Ronkanen, A., Kværner, J., Kløve, B., 2014. Runoff 417 Curve Numbers for Peat-Dominated Watersheds. Journal of Hydrologic Engineering. 040, 418 4058-1-04014058-10.

419 Nouri, H., Mason, R.J., Moradi, N., 2017. Land suitability evaluation for changing spatial 420 organization in Urmia County towards conservation of Urmia Lake. Appl.Geogr. 81, 1-12.

421 OWWMP, 2011a. Iran Ministry of Energy's Office for Water and Wastewater Macro422 Planning. Iran's comprehensive water resources plan. Agricultural Water use (Lake Urmia 423 Watershed) Report.

424 OWWMP, 2011b. Iran Ministry of Energy's Office for Water and Wastewater Macro425 Planning. Iran's comprehensive water resources plan. Meteorological Report.

426 OWWMP, 2011c. Iran Ministry of Energy's Office for Water and Wastewater Macro427 Planning. Iran's comprehensive water resources plan. Groundwater Studies (Lake Urmia 428 Watershed) Report.

429 Poff, N.L., Allan, J.D., Bain, M.B., Karr, J.R., Prestegaard, K.L., Richter, B.D., et al., 1997. 430 The natural flow regime: A paradigm for river conservation and restoration. Bioscience. 47, $431 \quad 769-784$.

432 Sabzghabaei, G.R., Monavari, S.M., Riazi, B., Khorasani, N., Karami, M., 2015. Analysing 433 pressures and threats on the Southern Wetlands of Iran with the application of RAPPAM 434 methodology (case study: Khuzestan Province). Global Nest J. 17, 344-356. 
Sima, S., Tajrishy, M., 2013. Using satellite data to extract volume-area-elevation relationships for Urmia Lake, Iran. J.Great Lakes Res. 39, 90-99.

437 Tharme, R.E., 2003. A global perspective on environmental flow assessment: Emerging trends 438 in the development and application of environmental flow methodologies for rivers. River 439 Res.Appl. 19, 397-441.

440 Torabi Haghighi, A., Klve, B., 2017. Design of environmental flow regimes to maintain lakes 441 and wetlands in regions with high seasonal irrigation demand. Ecol.Eng. 100, 120-129.

442 Torabi Haghighi, A., Menberu, M.W., Aminnezhad, M., Marttila, H., Kløve, B., 2016. Can 443 lake sensitivity to desiccation be predicted from lake geometry? J.Hydrol. 539, 599-610.

444 Torabi Haghighi, A., Kløve, B., 2015. A sensitivity analysis of lake water level response to 445 changes in climate and river regimes. Limnologica - Ecology and Management of Inland 446 Waters. 51, 118-130.

447 Tourian, M.J., Elmi, O., Chen, Q., Devaraju, B., Roohi, S., Sneeuw, N., 2015. A spaceborne 448 multisensor approach to monitor the desiccation of Lake Urmia in Iran. Remote Sens.Environ. $449 \quad 156,349-360$.

450 UNEP, GEAS, 2012. The Drying of Iran's Lake Urmia and its Environmental Consequences. 451 Environmental Development. 2, 128-137.

452 Xi, X., Sokolik, I.N., 2016. Quantifying the anthropogenic dust emission from agricultural land 453 use and desiccation of the Aral Sea in Central Asia. J.Geophys.Res.Atmos. 121, 12,270454 "12,281". 
(a)

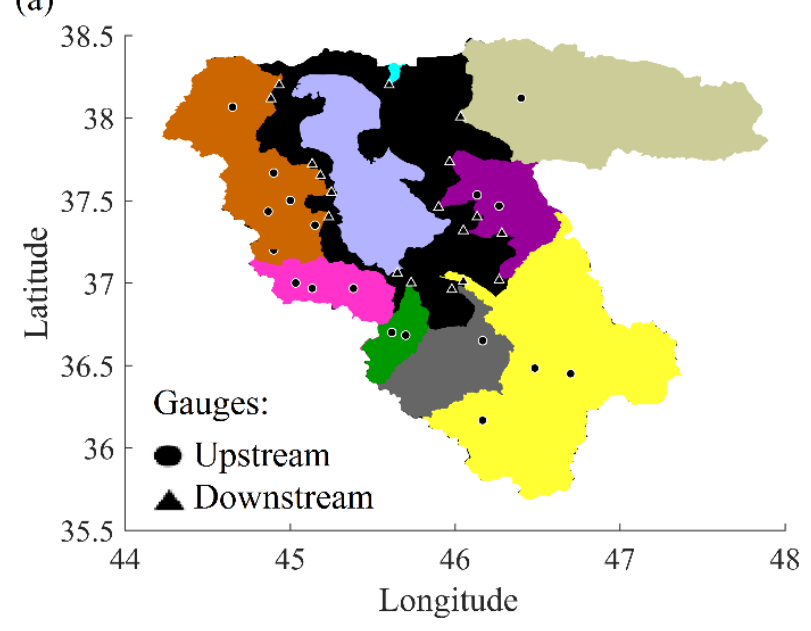

(b) $4.4 \mathrm{~km}^{3}$

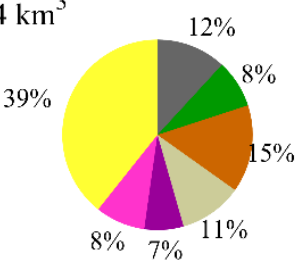

(d) $3.4 \mathrm{~km}^{3}$

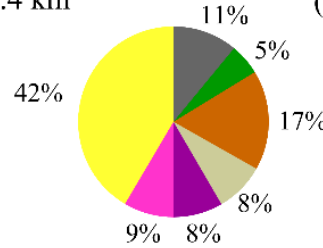

(c) $5 \mathrm{~km}^{3}$

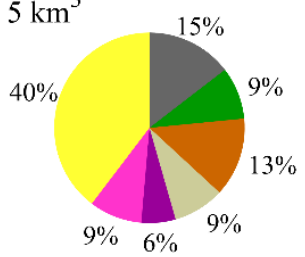

(e) $2.3 \mathrm{~km}^{3}$

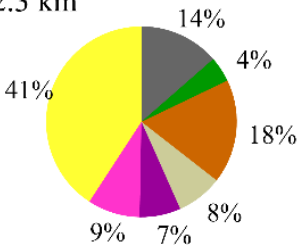

(f)

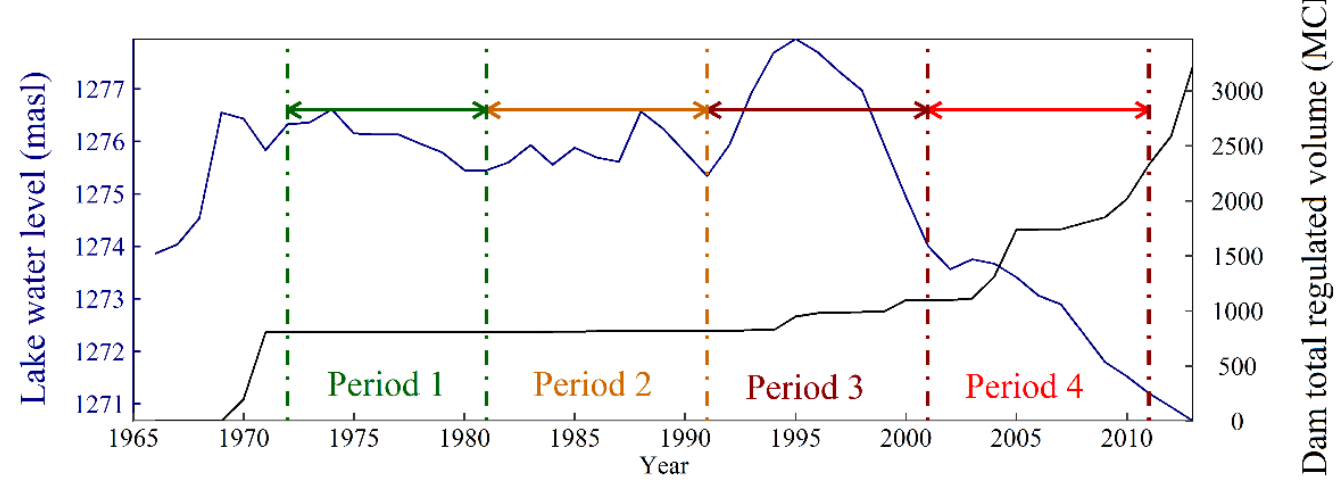

459

460

461

Fig. 1. a) Lake Urmia and its sub-basins and contribution of different sub-basins to lake inflow

462 in the period: b) 1972-1981, c) 1982-1991, d) 1992-2001, and e) 2002-2011. f) dam regulation volume and lake level changes for 1965-2011 (MCM: million cubic meter). 

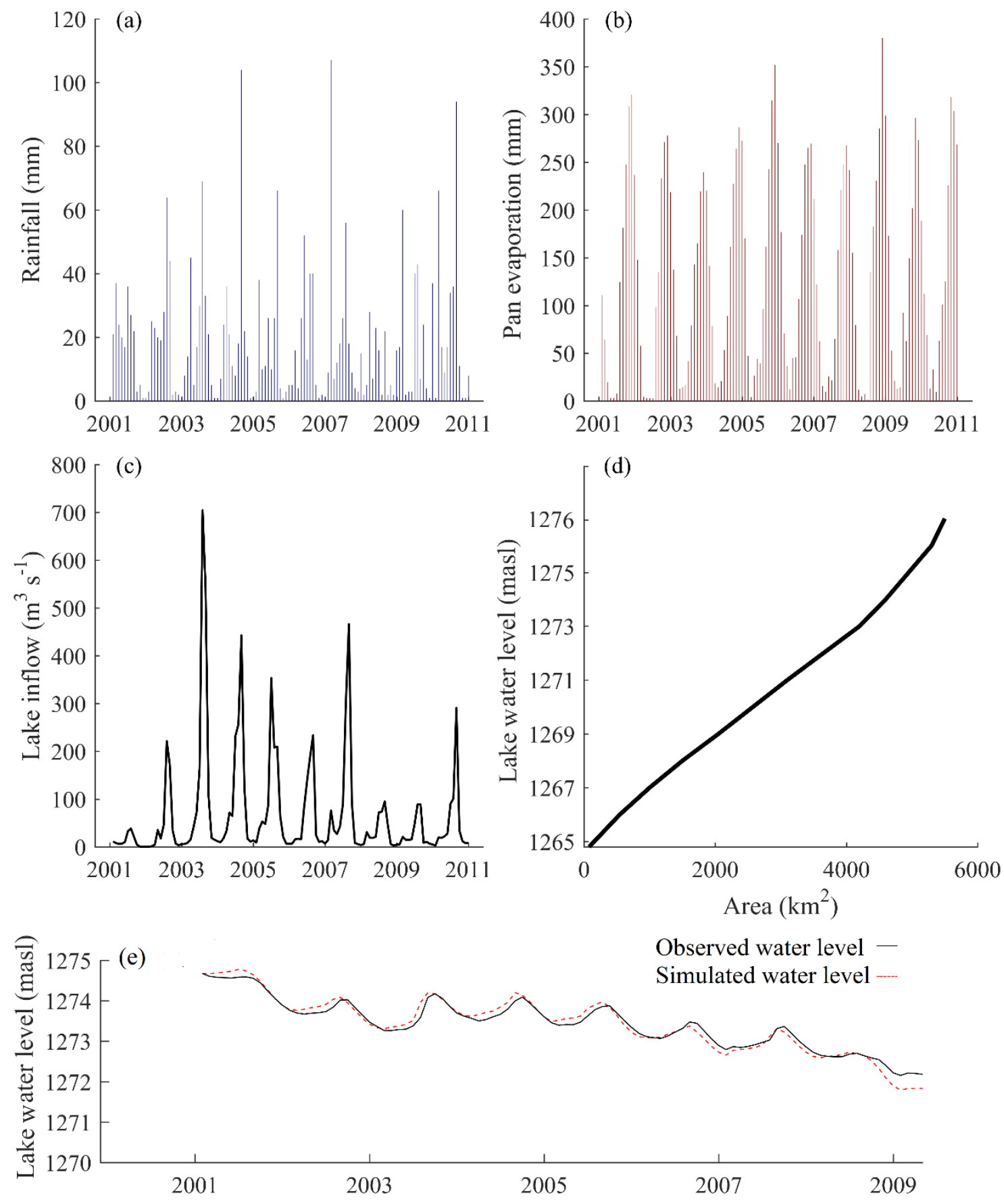
473 Fig. 2. Input data for Lake Urmia water balance simulation. a) rainfall (mm), b) pan evaporation

474 (mm), and c) inflow, September 2001- September 2010. d) area-water level curve of lake and

475 e) simulated and observed water level (2001-2009).

476

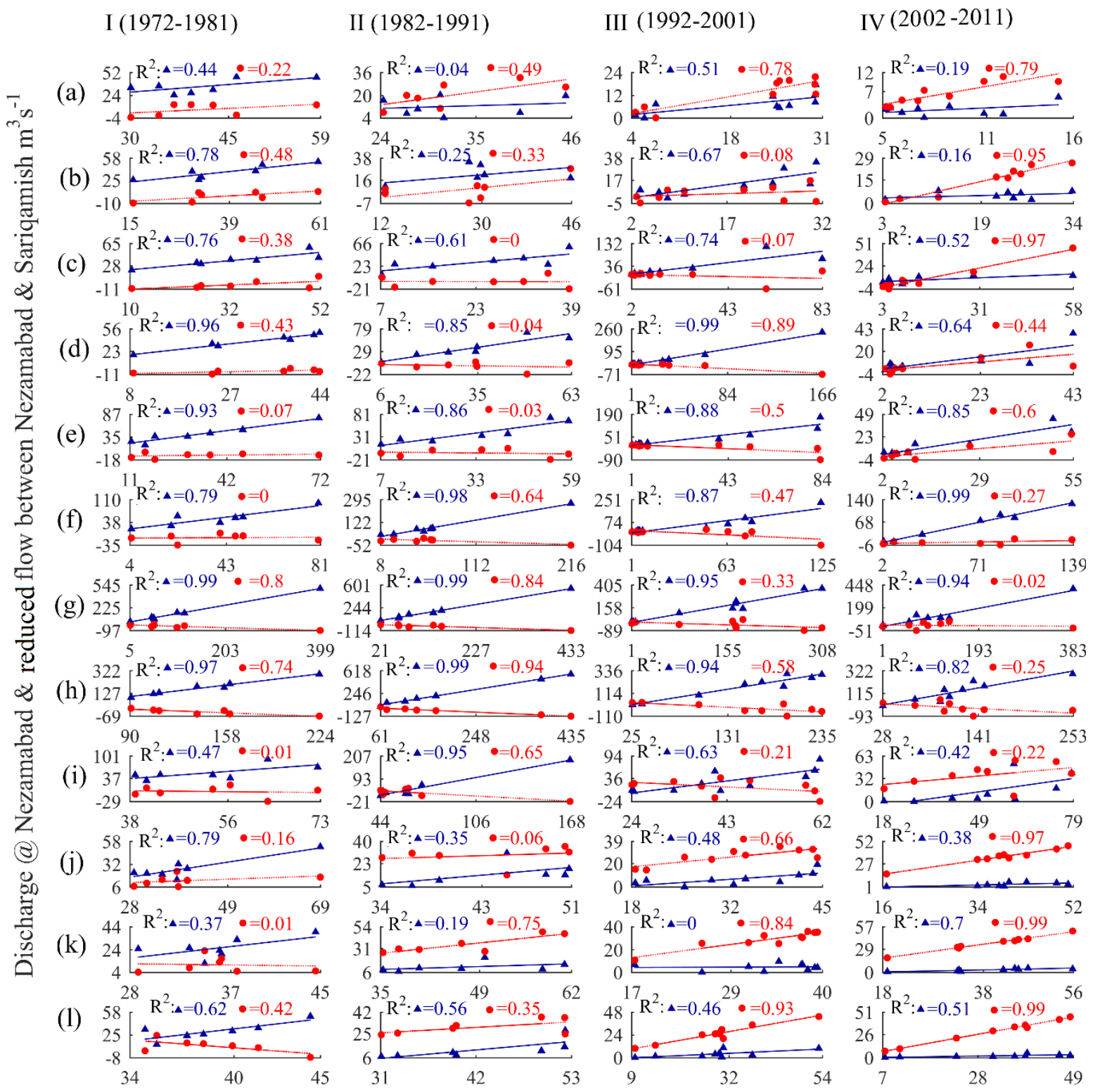

Discharge@, Sariqamish $\mathrm{m}^{3} \mathrm{~s}^{-1}$

478 Fig. 3. Upstream (Sariqamish gauge) and downstream (Nezamabad gauge) monthly (a-j:

479 October-September) flow relationship in the river Zarinehroud in different periods (I-IV). Blue

480 lines and triangles: regression line and points for Eq. 1, red line and circles: regression line and

481 points for Eq. 2. 


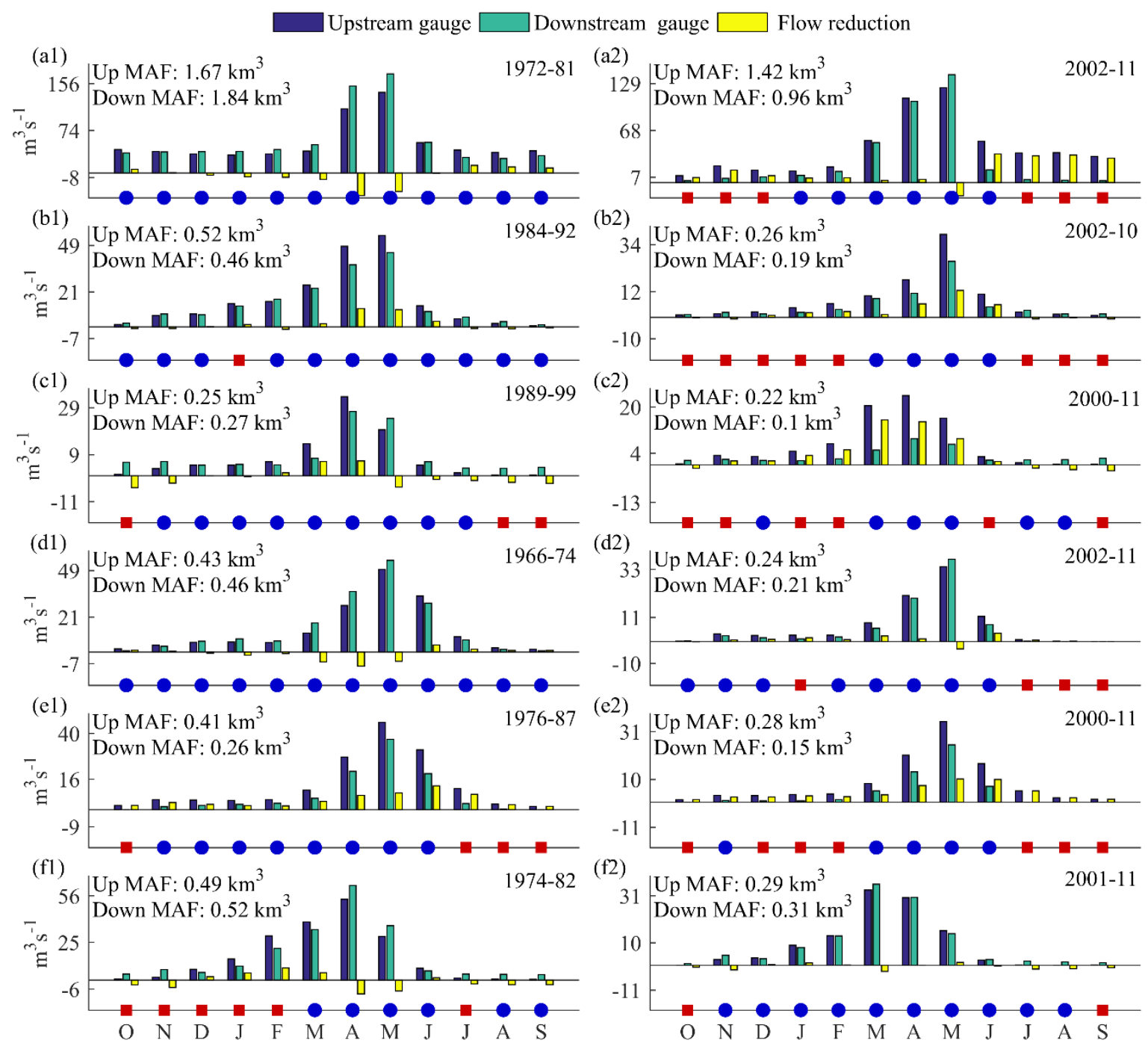

Fig. 4. River flow at the closest gauge to Lake Urmia (Down) and at upstream gauges (Up) in major rivers in the basin: a) Zarinehroud, b) Ajichay, c) Mahabadchay, d) Gadarchay, e) Nazluchay, and f) Siminehroud, where the suffixes 1 and 2 refer to earliest and latest period, respectively, when both gauges have flow data. Blue circles and red squares indicate whether Eq. 1 or 2, respectively, has the stronger regression coefficient, O-S: October-September, MAF: mean annual flow. 


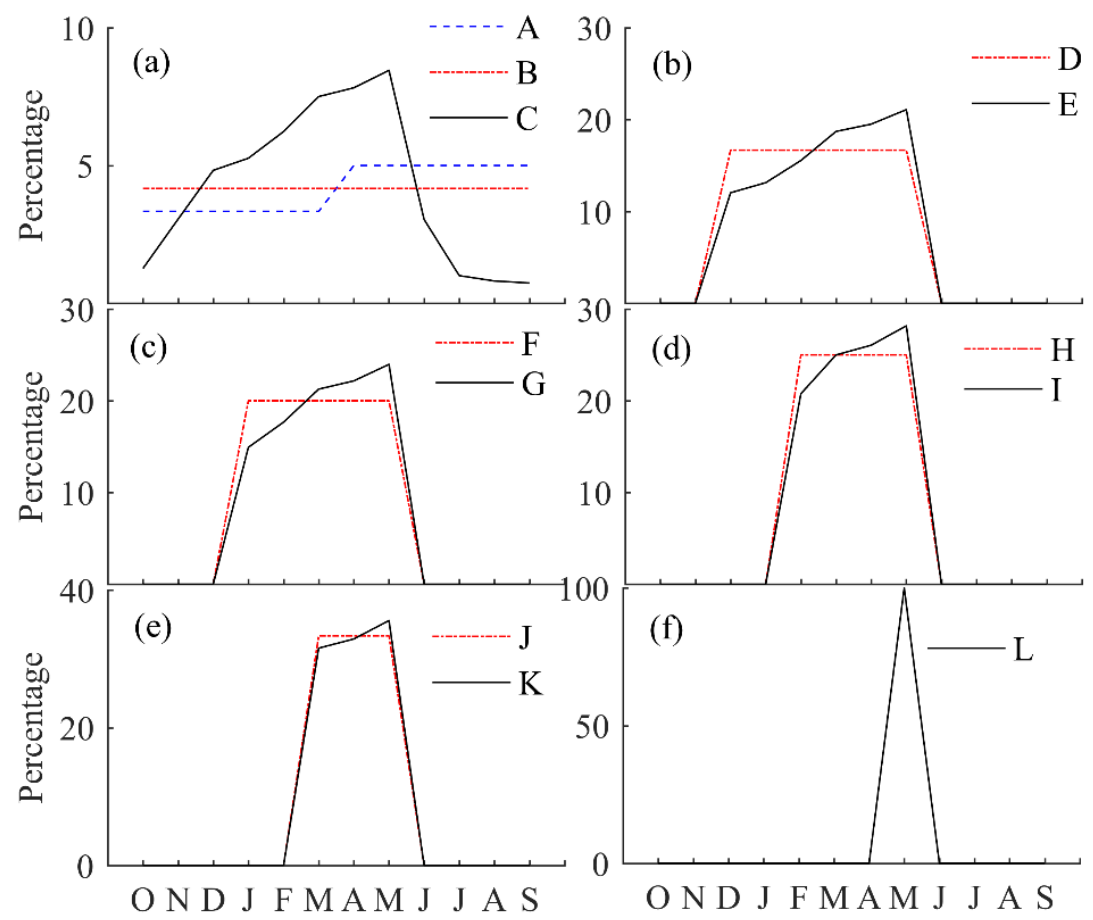

494 Fig. 5. Monthly distribution options for environmental flow (EF) release: a) twelve-month 495 release (A: Tennant, B: uniform, C: weighted), b) six-month release (D: uniform, E: weighted), 496 c) five-month release (F: uniform, G: weighted); d) four-month release (H: uniform, I: 497 weighted), e) three-month release (J: uniform, K: weighted), f) one-month release (L: uniform 498 or weighted).

499

500 


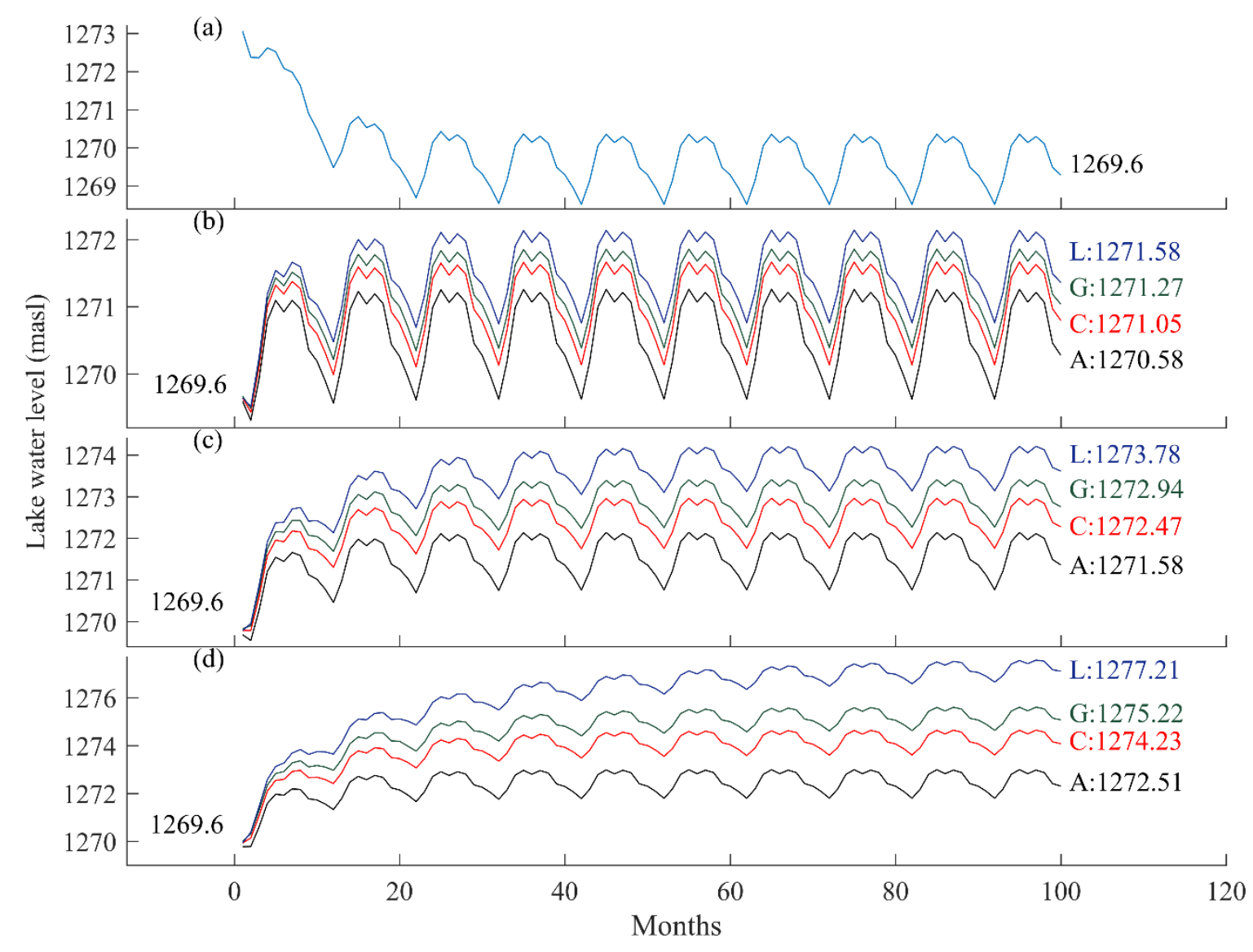

502

503 Fig. 6. Water level fluctuation in Lake Urmia. a) Long-term water level simulation to calculate 504 environmental water level (EWL) for the current situation (based on lake condition 2001505 2010). b, c, d) Performance of selected environmental flow (EF) release options (A and C: 506 Tennant and weighted twelve-month release, respectively; G: five-month weighted release; L: 507 one-month release) for three magnitudes of annual EF: 1.0, 2.0 and $3.0 \mathrm{~km}^{3}$. 


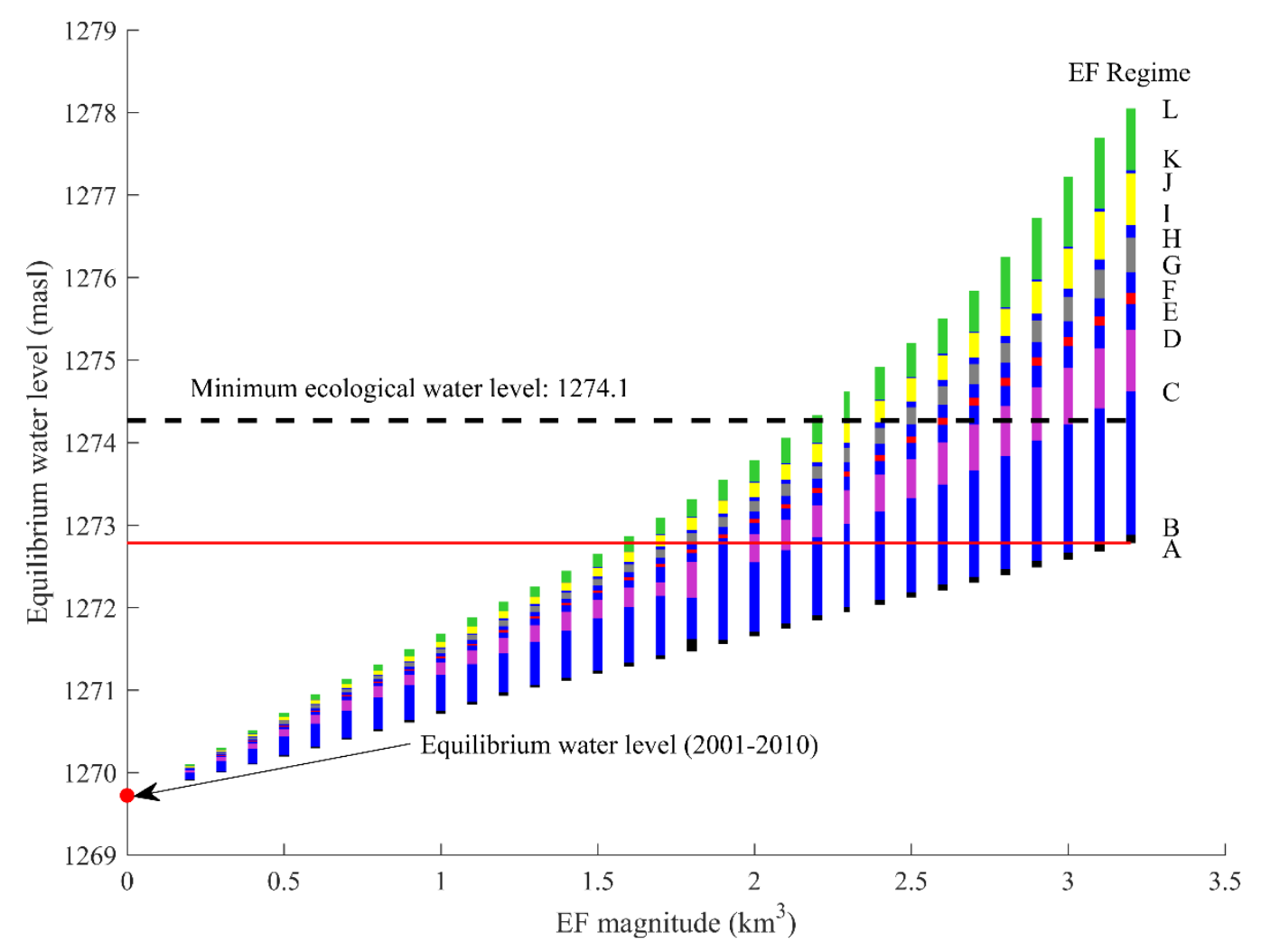

511

512 Fig. 7. Equilibrium water level (EWL) for different environmental flow (EF) scenarios. A

513 change in the color in each parallel line shows the water level increase when switching from 514 one EF release option (A-L) to other. 